OPEN ACCESS

Edited by:

lain Young,

University of Sydney, Australia

Reviewed by:

Frederic Gerard,

Institut National de la Recherche

Agronomique (INRA), France Andrea Carminati,

University of Bayreuth, Germany

*Correspondence:

Philippe C. Baveye

philippe.baveye@agroparistech.fr

Specialty section: This article was submitted to Soil Processes,

a section of the journal

Frontiers in Environmental Science

Received: 22 November 2018

Accepted: 13 February 2019

Published: 06 March 2019

Citation:

Baveye PC and Wander M (2019) The (Bio)Chemistry of Soil Humus and

Humic Substances: Why Is the "New View" Still Considered Novel After More Than 80 Years?

Front. Environ. Sci. 7:27. doi: 10.3389/fenvs.2019.00027

\section{The (Bio)Chemistry of Soil Humus and Humic Substances: Why Is the "New View" Still Considered Novel After More Than 80 Years?}

\author{
Philippe C. Baveye ${ }^{1 *}$ and Michelle Wander ${ }^{2}$ \\ ${ }^{1}$ ECOSYS Unit, AgroParisTech, Université Paris-Saclay, Thiverval-Grignon, France, ${ }^{2}$ Department of Natural Resources and \\ Environmental Sciences, University of Illinois at Urbana-Champaign, Urbana, IL, United States
}

Three years ago, a novel "soil continuum model" was proposed, in which soil organic matter was suggested to be of heterogeneous composition and to consist of a continuum of organic fragments of all sizes. A search of the literature reveals that this model is identical to several similar conceptualizations proposed about 15 years ago, and that it corresponds closely with the description of humic substances given in Waksman's (1936) remarkably thorough book on the topic, which also emphasized the intimate connections existing between humic substances and soil microorganisms. Several historical reasons, reviewed in this Perspective article, may explain why Waksman's viewpoint might still be considered novel more than 80 years later. Here we argue that the key reason for the agonizingly slow rate of progress in the field is linked to the extreme compartmentalization of research and education in soil science, which has been organized along distinct subdisciplines, with the result that interdisciplinary efforts that are desperately needed to understand the dynamics of soil humic substances are very hard to launch. To meet growing demands on soils we have to understand the mechanisms that underpin their many functions. To gain this understanding and finally make badly needed progress, we must reorganize funding and educational efforts to support exploration of "Waksman's frontier," which includes the microscale where the microbial, physical and biochemical processes governing organic matter turnover occur.

Keywords: humus, humification, soil organic matter, paradigm (gestalt) shift, Waksman

In 1936, slightly over 80 years ago, Selman Waksman published a momentous and monumental book in which he reviewed in great detail what was known and not known at the time about the origin, chemical composition, and importance of humus. This book must have required a phenomenal amount of work. Indeed, in order to write it, Waksman collected and analyzed a whopping number (1311) of primary sources spanning several centuries, some in German, French, Russian, and Latin. Even with all the electronic databases available to us nowadays, this would be an extremely time-consuming endeavor, requiring many months, if not years, of full-time reading and excerpting. In the 1930s, without internet, photocopy machines, or the option of e-mailing colleagues to get reprints of their publications, identifying, let alone reviewing 1311 sources must have been an absolutely formidable undertaking, well worth celebrating in its own right.

Apparently influenced by a number of earlier German authors, whom he cited, Waksman (1936) defined humus as follows: "Chemically, humus consists of certain constituents of the original plant 
material resistant to further decomposition; of substances undergoing decomposition; of complexes resulting from decomposition, either by processes of hydrolysis or by oxidation and reduction; and of various compounds synthesized by microorganisms." A decade earlier, Waksman (1925) had been a strong advocate of the traditional practice of extracting soil organic matter with alkali, followed by the identification, based on water solubility, of three different categories of highmolecular weight, inherently stable, and chemically unique "humic substances" (fulvic acid, humic acid, and humin). However, by 1936 he had changed his mind on the matter, being convinced that alkali extracts were a strictly operational, arbitrary construct, which "fails to give a picture of the true nature of humus, its origin, and its dynamic condition in the soil." His writings suggest that the idea that humic substances could have a unique or definitive chemical structure dates to the time when "chemistry was still in its infancy and when all organic and inorganic compounds were considered to be substances very simple in chemical composition." A microbiologist by training, Waksman also kept insisting heavily, throughout his book, on the fundamental, but too often ignored, "invisible ties" connecting humus and living microorganisms, "which must be appreciated in order to understand the origin and nature of humus." He argued that, "without denying the role of purely chemical reactions in the formation and transformation of humus, especially those of oxidation and reduction, hydrolysis and polymerization, it should be recognized that the primary agents in the formation and transformation of humus are the microorganisms; by overlooking their functions, the earlier chemists failed to understand the origin and significance of humus, in spite of the many years of effort, from the beginnings of organic chemistry until recent times."

Given the clarity of Waksman's (1936) summary of the state of knowledge of humus and roadmap for future research, it is surprising that nobody followed up on his suggestions until the 90s, more than half a century later. Insofar as Waksman himself is concerned, there is a relatively simple reason, linked to inauspicious timing, why he did not pursue work along the path he had so painstakingly outlined. As also happened in the case of Langmuir's (1938) seminal work on electrostatic interactions between charged particles (McBride and Baveye, 2002), world events of the late 30s rapidly prompted Waksman to shift his attention away from important work toward more pressing matters. After Dubos (1939) managed to isolate for the first time an antibiotic (gramicidin) produced by a soil microorganism, the enormous practical consequences of this fundamental breakthrough for health care, and especially for the treatment of wounded soldiers, became rapidly obvious (Moberg, 1999; Van Epps, 2006). To find other antibiotics, the pharmaceutical industry started financing systematic testing programs, including a large one in Waksman's laboratory after 1939. In 1942, Albert Schatz, one of Waksman's assistants working with Actinomycetes, discovered streptomycin. The bitter legal battle over royalties that ensued between Schatz and Waksman (e.g., Lawrence, 2002; Kingston, 2004; Casadevall and Fang, 2013; Pringle, 2013), and the award of the Nobel Prize in medicine to Waksman in 1952 caused him to focus virtually all his later attention to antibiotics. We find no evidence that he ever resumed his work on humus or its interactions with microorganisms.

This does not explain, however, why other soil microbiologists did not pick up where Waksman left off. To some extent, an answer to this question can be found in reflections Waksman made later (Waksman, 1958) when he pointed out that soil scientists demonstrated very little recognition toward soil microbiology in the early part of the twentieth century. The emphasis in soil science was instead on the physics and chemistry of soils, particularly in relation to soil fertility, or on soil classification. That state of affairs was still manifestly ongoing in 1936, as illustrated by the fact that during that year, the journal Soil Science contained only 6 articles dealing with soil microorganisms out of a total of 77 articles, while the Proceedings of the Soil Science Society of America did not contain a single article related to soil microbiology. The dominance of one view, the chemist's view, explains why the opinion of a soil microbiologist on the nature of what was perceived essentially as a chemical component of soils is likely to have fallen on relatively deaf ears. Equally so, most probably, is Waksman's viewpoint that future research on humus should be what we would now call "multidisciplinary" or even "interdisciplinary" (Baveye et al., 2014). Waksman (1936) saw clearly that the close connection he identified between soil microorganisms and the nature of soil humic substances required a research approach involving the cooperation of several disciplines. In his opinion, the "physicist, the chemist, the botanist, and the microbiologist can all contribute to the solution of the numerous complicated problems involved in the formation and utilization of humus." However, it was far more in keeping with the habits of the time for soil chemists to keep doing what they had been trained to do, i.e., extract chemical compounds from soils and try to determine their unique and hypothetically welldefined, high-molecular-weight chemical structure, an endeavor that they pursued with great energy and conviction for several decades, totally independently of what soil physicists and microbiologists, housed in the same organizations, were doing on their side.

In all fairness, for many years, an additional difficulty was that it was not really feasible in practice to carry out the type of interdisciplinary research Waksman had envisioned in 1936. In the 50 and 60s, several microbiologists (e.g., Alexander, 1965; Griffith, 1965) also came to the conclusion that to understand the activity of microorganisms in soils, a detailed analysis at the spatial scale of microorganisms (i.e., at the "microscale") was required. But, unfortunately, "inherent technical difficulties in biochemical experimentation at the microscopic level" (Alexander, 1965) severely hindered progress in that direction. The advent of transmission or scanning electron microscopes, in the 60 and 70s, provided a wealth of qualitative information about microbial habitats as seen in micrographs of increasingly high quality (e.g., Foster, 1988). However, that new information could not be correlated with corresponding microscopic data about the composition of organic matter, because relevant chemical analysis methods remained almost entirely macroscopic. 
Nevertheless, progress in several spectroscopic analysis techniques, in particular in various Nuclear Magnetic Resonance methods, during the 90s enabled researchers to characterize the chemical composition of humic substances in soils in much more detail, and to confirm the soundness of Waksman's (1936) perspective. In a landmark review article, Piccolo (2002) concluded that humic substances are "supramolecular associations of self-assembling heterogeneous and relatively small molecules deriving from the degradation and decomposition of dead biological material." Others at about the same time expressed similar views as well, based on their reading of the literature (e.g., Burdon, 2001; Wander, 2004). A few years later, in a thorough and widely-cited review of independent analytical research carried out over the previous decade, Sutton and Sposito (2005) referred to humic substances as "collections of diverse, relatively low molecular mass components forming dynamic associations stabilized by hydrophobic interactions and hydrogen bonds." Of special mention in the publications of that period are molecular aggregation models (Wershaw, 1986, 1999; Piccolo, 2001; Kleber et al., 2007; Chilom et al., 2009), which describe the role that lipid-humic interactions play in soil organic matter formation. One could consider this the one "new" idea that use of classical extraction methods has added to our conceptualization of soil organic matter that was established at the turn of the century.

At approximately the same time as the publication of Sutton and Sposito's (2005) review, the commercialization of tabletop X-ray computed tomography equipment made it possible to quantify the geometry and topology of the pore space in soils (e.g., Young and Crawford, 2004; O’Donnell et al., 2007). Dedicated beamlines at synchrotron facilities around the world allowed soil scientists and geochemists to perform measurements of a number of soil chemical characteristics at nanometric and micrometric scales, using techniques like $\mathrm{X}$-ray absorption near-edge structure (XANES) or near-edge X-ray absorption fine structure (NEXAFS) spectroscopy. Finally, routine access to novel types of microscopy, like fluorescence or confocal laser microscopes, made quantitative data available for the first time on bacterial cell distribution (e.g., Nunan et al., 2003; Eickhorst and Tippkötter, 2008). In many ways, all the stars were aligned, metaphorically speaking, to launch in earnest the interdisciplinary research program on humic substances that Waksman (1936) had envisaged decades ago. There were some limited attempts in that sense. Indeed, at about the same time Sutton and Sposito (2005) concluded from their review of the literature that "humic components display contrasting molecular motional behavior and may be spatially segregated on a scale of nanometers," XANES and NEXAFS analyses were able to provide clear visual evidence that the latter part of that statement was indeed the rule, in representative soils (Jokic et al., 2003; Schumacher et al., 2005; Solomon et al., 2005; Kinyangi et al., 2006). But beyond this limited confirmation, no real integration of techniques and disciplinary perspectives took place, and little progress was made for another decade on the chemistry and dynamics of humic substances. Most humics research continued to describe organic matter in an averaged, macroscopic sense, restricting our ability to understand connections between the biotic and abiotic components of soils and soil functions. While each of the individual disciplinary perspectives has been explored further, sometimes in great depth, reluctance, intransigence, or disciplinary inertia continue to prevent researchers from putting the pieces of the puzzle together to finally allow us to understand in detail how microorganisms influence the creation and transformation humic substances, or the factors that control these processes (Baveye et al., 2018).

Ten years almost to the day after Sutton and Sposito's (2005) synthesis, Lehmann and Kleber (2015), in a well-crafted article, reviewed in detail a number of different opinions held about the chemical nature of soil organic matter and proposed the "soil continuum model" (SCM) ${ }^{1}$. This model conceptualizes soil organic matter, not as a collection of high-molecular weight macromolecules (i.e., the "traditional view"), but as a "continuum" of organic fragments of all sizes "spanning the full range from intact plant material to highly oxidized carbon in carboxylic acids." These organic fragments are "continuously processed by the decomposer community toward smaller molecular size." Despite illustrative diagrams contrasting the SCM with the "traditional view," and the claim that the SCM offers a new "way forward in modeling soil carbon dynamics and developing soil management that is based on observable evidence," it is hard to see any significant advance in this model relative to the "new view" of humic substances described 80 years earlier by Waksman (1936), or to the views echoed more recently by Piccolo (2002) and Sutton and Sposito (2005). Concerning the dynamics of humic substances, Lehmann and Kleber (2015) call for methods that produce "observable evidence," needed to obtain "reliable predictions of soil organic matter turnover," and which allow us to study organic matter's "spatial arrangement within the mineral matrix, the fine-scale redox environment, microbial ecology and interaction with mineral surfaces under moisture and temperature conditions observed in soils." They also reiterate Waksman's observation that the extraction of humic substances does not provide a realistic picture of the true composition and properties of organic matter that exists in soils, and recommended that terms like "humus," "humification," or even "humic substances," routinely used for centuries, should no longer be part of the vocabulary of soil scientists.

Over the last 3 years, the different suggestions of Lehmann and Kleber (2015) have caused quite a stir among soil scientists (e.g., Piccolo, 2016; Gerke, 2018; Hayes and Swift, 2018; Weber et al., 2018; Olt et al., in press). Defenses of entrenched habits against what is portrayed almost as a heresy have been extremely passionate, and the negative reactions to the proposals made have been very adamant. This is illustrated vividly by two special issues published recently by the Journal of Soils and Sediments, one celebrating Frank Stevenson's work on soil organic matter (Knicker et al., 2018) and the other devoted to humic substances (Weber et al., 2018). Both special issues contain many articles still dealing explicitly with alkali extracts and arguing the inherent merits of this approach. Regarding the recommendation, made

\footnotetext{
${ }^{1}$ This terminology is somewhat unfortunate because it has been in use in geotechnical engineering for many years, to describe an entirely different concept (e.g., Kraft et al., 1985; Chiaramonte et al., 2013)
} 
by Lehmann and Kleber (2015), to abandon the "humus" terminology, there has been as yet very little open debate in the literature on whether sanctioning terms that are routinely used in the public sphere makes sense and should, or even could, be adopted widely. According to the Web of Science, it does not appear that Lehmann and Kleber's (2015) recommendation has been well-received, since the number of published articles referring to "humus" or "humification" in soils has not decreased at all since 2015. Instead of sanctioning the use of these historyladen terms, it might be better to follow Waksman's (1936) lead, and simply make sure that they be appropriately defined.

In all the uproar that followed the publication of Lehmann and Kleber's (2015) article, little attention unfortunately seems to have been devoted to the chemical nature and dynamics of humic substances, making it likely that we are going to witness once again what Jenny (1961), writing about soil acidity, once referred to sarcastically as a "merry-goround": There is a good chance that another Science or Nature article will be published in about 2025, extolling anew Waksman's perpetually "emergent" perspective on soil humus. However, from a more optimistic perspective, the soil science community may yet decide to take up Lehmann and Kleber's research agenda and, critically, note that the tools needed to answer their call and improve our understanding of the dynamics of soil organic matter at the microscale already exist, indeed have been available for a decade, but have remained largely unused.

It would be crucial in this context to understand the key reasons why opportunities available for the microscale analysis of humic substances in soils have not been seized from 2005 until recently, in order to avoid pitfalls or repeating the mistakes made. In this respect, it seems to us that the most likely explanation for our current state of affairs, and for the very slow movement forward concerning the nature and dynamics of humic substances, is related to the existence of a sizeable barrier on the path to interdisciplinary research. There may conceivably be several causes for such a barrier. Interdisciplinary efforts are notoriously difficult to launch, because of institutional constraints and funding mechanisms that often strongly favor mono-disciplinary endeavors (e.g., Baveye et al., 2014). Another reason is that microbiology has increasingly evolved over the last 3 decades away from ecology along lines that parallel the development of modern agricultural chemistry and initially caused divisions between the biological and physical sciences back in Waksman's day (Wander, 2009). Much of the research in soil microbiology over the last two decades has been predicated on the notion that the physical or chemical properties of microenvironments where microorganisms reside in soils are irrelevant, and that extracted DNA or RNA molecules contain all the information that is needed to make sense of the activity of microbes in soils. The adoption of this approach has had the merit to generate macroscopic or bulk representations of community composition that satisfy demands for reproducible quantitative measures. However, during the last two decades, this perspective, which has attracted growing criticism (e.g., O'Donnell et al., 2007; Baveye, 2009; Baveye et al., 2018; Young and Bengough, 2018), has arguably contributed in a significant manner to thwart interdisciplinary research efforts dealing with soil microorganisms, and has led microbiologists into the same trap that has constrained progress by soil chemists and physicists working at the macroscopic scale.

To break out of that trap, we need to recognize how we have organized and compartmentalized the discipline of soil science. The inner workings of our scholarly societies, with separate divisions associated with soil physics, soil chemistry, and so on, demonstrate that we still perceive our discipline as being strongly organized according to a number of distinct subdisciplines. This structuring of soil science has been criticized for many years. Gardner (1991), for example, admonished us to be aware of the fact that "if soil science is to continue and prosper as a scientific discipline in its own right, it will be through successful integration of the advances in each subdiscipline into an integral whole." In spite of repeated advice along those lines, nothing much has happened. Worse yet, with a few notable exceptions (e.g., foundational agroecology programs), the training of the next generation of soil scientists has not evolved much either toward more disciplinary integration. Aside from the notable exception of programs emphasizing problem-based learning (Amador and Görres, 2004; Amador et al., 2006), lectures in most soil science degree programs still focus solely on single subdisciplines, and specialization of soil science students occurs too early and is far too pronounced. Sadly, it is not inconceivable today, e.g., for a soil physicist to know nothing about the ecology of soil meso- or macro-fauna, or for a soil microbiologist to be unaware of how the intricate geometry of the pore space in soils affects microorganisms. Every year, worldwide, soil science education programs produce large numbers of graduates handicapped by this kind of crippling ignorance.

And yet, in spite of the clear deficiencies of our educational systems, there appear to be reasons for hope. Not only has a group of predominantly young researchers recently called for increasing emphasis on interdisciplinary research in soil science (Baveye et al., 2018), but this call has been rapidly followed by significant steps along this path. Vidal et al. (2018) have combined different spectroscopic and microscopic techniques to simultaneously gain information about the distribution of minerals and biomass in the vicinity of roots. More recently, Schlüter et al. (2019), using a combination of X-ray $\mu \mathrm{CT}$, fluorescence microscopy, scanning electron microscopy and nanoSIMS, were able to study the distribution of bacteria in a soil, and to show that they have a preference toward foraging near macropore surfaces and near fresh particulate organic matter. This pioneering interdisciplinary research opens the path toward the micro- and mesoscale analysis not just of the dynamics of soil organic matter, and related processes like priming or the storage and protection of carbon, which are eminently relevant in the context of global climate change, but also of other soil-borne processes of great practical importance, like the regulation of soil acidity and the binding of metals, about which various questions have remained unanswered, in spite of a sizeable research effort in the past (e.g., Tipping and Hurley, 1988; Tipping, 2002). 
Given the key functions that soils fulfill in a number of environmental contexts, not to forget with respect to the daunting objective of feeding 10 billion inhabitants on earth by 2050 (e.g., Baveye, 2015), it would be simply unacceptable not just for the discipline of soil science, but also for society at large, if we did not break the interdisciplinary barrier that has stood in our path so far. Understanding the dynamics of soil humic substances

\section{REFERENCES}

Alexander, M. (1965). Biodegradation: problems of molecular recalcitrance and microbial fallibility. Adv. Appl. Microbiol. 7, 35-80. doi: 10.1016/S0065-2164(08)70383-6

Amador, J. A., and Görres, J. H. (2004). A problem-based learning approach to teaching introductory soil science. J. Nat. Resour. Life Sci. Educ. 33, 21-27. Available online at: https://www.agronomy.org/files/jnrlse/issues/2004/e03-19. pdf.

Amador, J. A., Miles, L., and Peters, C. B. (2006). The Practice of Problem-Based Learning: A Guide to Implementing PBL in the College Classroom. San Francisco, CA: Jossey-Bass.

Baveye, P. C. (2009). To sequence or not to sequence the whole-soil metagenome? Nat. Rev. Microbiol. 7:756. doi: 10.1038/nrmicro2119-c2

Baveye, P. C. (2015). Grand challenges in the research on soil processes. Front. Environ. Sci. 3:10. doi: 10.3389/fenvs.2015.00010

Baveye, P. C., Otten, W., Kravchenko, A., Balseiro Romero, M., Beckers, É., Chalhoub, M., et al. (2018). Emergent properties of microbial activity in heterogeneous soil microenvironments: different research approaches are slowly converging, yet major challenges remain. Front. Microbiol. 8:1364. doi: $10.3389 /$ fmicb.2017.01364

Baveye, P. C., Palfreyman, J., and Otten, W. (2014). Research efforts involving several disciplines: adherence to a clear nomenclature is needed. Water Air Soil Pollut. 225:1997. doi: 10.1007/s11270-014-1997-7

Burdon, J. (2001). Are the traditional concepts of the structures of humic substances realistic? Soil Sci. 166, 752-769. doi: 10.1097/00010694-200111000-00004

Casadevall, A., and Fang, F. C. (2013). Is the Nobel Prize good for science? FASEB J. 27, 4682-4690. doi: 10.1096/fj.13-238758

Chiaramonte, M. M., Arduino, P., Lehman, D. E., and Roder, C. W. (2013). Seismic analyses of conventional and improved marginal wharves. Earthquake Eng. Struct. Dyn. 42, 1435-1450. doi: 10.1002/eqe.2280

Chilom, G., Bruns, A. S., and Rice, J. A. (2009). Aggregation of humic acid in solution: contributions of different fractions. Org. Geochem. 40, 455-460. doi: 10.1016/j.orggeochem.2009.01.010

Dubos, R. (1939). Bactericidal effect of an extract of a soil bacillus on Grampositive cocci. Proc. Soc. Exp. Biol. Med. 40:311-312. doi: 10.3181/00379727-40$10395 \mathrm{P}$

Eickhorst, T., and Tippkötter, R. (2008). Detection of microorganisms in undisturbed soil by combining fluorescence in situ hybridization (FISH) and micropedological methods. Soil Biol. Biochem. 40, 1284-1293. doi: 10.1016/j.soilbio.2007.06.019

Foster, R. C. (1988). Microenvironments of soil microorganisms. Biol. Fert. Soils 6, 189-203. doi: 10.1007/BF00260816

Gardner, W. R. (1991). Soil science as a basic science. Soil Sci. 151, 2-6. doi: 10.1097/00010694-199101000-00002

Gerke, J. (2018). Concepts and misconceptions of humic substances as the stable part of soil organic matter: a review. Agronomy 8:76. doi: 10.3390/agronomy8050076

Griffith, E. (1965). Micro-organisms and soil structure. Biol. Rev. Camb. Philos. Soc. 40, 129-142. doi: 10.1111/j.1469-185X.1965.tb00799.x

Hayes, M. H. B., and Swift, R. S. (2018). An appreciation of the contribution of Frank Stevenson to the advancement of studies of soil organic matter and humic substances. J. Soils Sediments 18, 1212-1231. doi: 10.1007/s11368-018-1636-6 and natural organic matter is too crucial for us to avoid yet again taking the path not traveled.

\section{AUTHOR CONTRIBUTIONS}

$\mathrm{PB}$ and MW both have contributed to the content of this article and collaborated closely in its writing.

Jenny, H. (1961). Reflections on the soil acidity merry-go-round. Soil Sci. Soc. Am. Proc. 25, 428-432. doi: 10.2136/sssaj1961.03615995002500060006x

Jokic, A., Cutler, J. N., Ponomarenko, E., van der Kamp, G., and Anderson, D. W. (2003). Organic carbon and sulphur compounds in wetland soils: insights on structure and transformation processes using K-edge XANES and NMR spectroscopy. Geochim. Cosmochim. Acta 67, 2585-2597. doi: 10.1016/S0016-703700101-7

Kingston, W. (2004). Streptomycin, Schatz vs Waksman, and the balance of credit for discovery. J. Hist. Med. Allied Sci. 59, 331-462. doi: 10.1093/jhmas/jrh091

Kinyangi, J., Solomon, D., Liang, B., Lerotic, M., Wirick, S., and Lehmann, J. (2006). Nanoscale biogeocomplexity of the organomineral assemblage in soil: application of STXM microscopy and C 1s-NEXAFS spectroscopy. Soil Sci. Soc. Am. J. 70, 1708-1718. doi: 10.2136/sssaj2005.0351

Kleber, M., Sollins, P., and Sutton, R. (2007). A conceptual model of organo-mineral interactions in soils: self-assembly of organic molecular fragments into zonal structures on mineral surfaces. Biogeochemistry 85, 9-24. doi: 10.1007/s10533-007-9103-5

Knicker, H., Rosario-Ortiz, F. L., and Zaccone, C. (2018). Preface - special issue in memory of Frank J. Stevenon. J. Soils Sediments 18, 1209-1211. doi: 10.1007/s11368-018-1955-x

Kraft, L. M., Helfrich, S. C., Suhayda, J. N., and Marin, J. E. (1985). Soil response to ocean waves. Mar. Geotechnol. 6, 173-203. doi: 10.1080/10641198509388186

Langmuir, I. (1938). The role of attractive and repulsive forces in the formation of tactoids, thixotropic gels, protein crystals and coacervates. J. Chem. Phys. 6, 873-896. doi: 10.1063/1.1750183

Lawrence, P. A. (2002). Rank injustice: the misallocation of credit is endemic in science. Nature 415, 835-836. doi: 10.1038/415835a

Lehmann, J., and Kleber, M. (2015). The contentious nature of soil organic matter. Nature 528, 60-68. doi: 10.1038/nature16069

McBride, M. B., and Baveye, P. (2002). Diffuse double-layer models, long-range forces, and ordering in clay colloids. Soil Sci. Soc. Am. J. 66, 1207-1217. doi: 10.2136/sssaj2002.1207

Moberg, C. L. (1999). René Dubos, a harbinger of microbial resistance to antibiotics. Perspect. Biol. Med. 42, 559-580. doi: 10.1353/pbm.1999.0011

Nunan, N., Wu, K. J., Young, I. M., Crawford, J. W., and Ritz, K. (2003). Spatial distribution of bacterial communities and their relationships with the micro-architecture of soil. FEMS Microbiol. Ecol. 44, 203-215. doi: 10.1016/S0168-649600027-8

O’Donnell, A. G., Young, I. M., Rushton, S. P., Shirley, M. D., and Crawford, J. W. (2007). Visualization, modelling and prediction in soil microbiology. Nat. Rev. Microbiol. 5, 689-699. doi: 10.1038/nrmicro1714

Olt, D. C., Bloom, P. R., Perdue, E. M., Chen, Y., McKnight, D. M., Farenhorst, A., et al. (in press). Environmental and agricultural relevance of humic fractions extracted by alkali from soils and natural waters. J Envirn Qual. doi: $10.2134 /$ jeq2019.02.0041

Piccolo, A. (2001). The supramolecular structure of humic substances. Soil Sci. 166, 810-832. doi: 10.1097/00010694-200111000-00007

Piccolo, A. (2002). The supramolecular structure of humic substances. A novel understanding of humus chemistry and implications in soil Science. $A d v$. Agron. 75, 57-134. doi: 10.1016/S0065-2113(02)75003-7

Piccolo, A. (2016). In memoriam Prof. F. J. Stevenson and the question of humic substances in soil. Chem. Biol. Technol. Agric. 3:23. doi: 10.1186/s40538-016-0076-2

Pringle, P. (2013). Experiment Eleven: Dark Secrets Behind the Discovery of a Wonder Drug. New York, NY: Bloomsbury Publishing. 
Schlüter, S., Eickhort, T., and Mueller, C. W. (2019). Correlative imaging reveals holistic view of soil microenvironments. Environ. Sci. Technol. 53, 829-837. doi: 10.1021/acs.est.8b05245

Schumacher, M., Christl, I., Scheinost, A. C., Jacobsen, C., and Kretzschmar, R. (2005). Chemical heterogeneity of organic soil colloids investigated by scanning transmission X-ray microscopy and C-1s NEXAFS microspectroscopy. Environ. Sci. Technol. 39, 9094-9100. doi: 10.1021/es050099f

Solomon, D., Lehmann, J., Kinyangi, J., Liang, B., and Schäfer, T. (2005). Carbon K-edge NEXAFS and FTIR-ATR spectroscopic investigation of organic carbon speciation in soils. Soil Sci. Soc. Am. J. 69, 107-119. doi: 10.2136/sssaj2005.0107dup

Sutton, R., and Sposito, G. (2005). Molecular structure in soil humic substances: the new view. Environ. Sci. Technol. 39, 9009-9015. doi: 10.1021/es050778q

Tipping, E. (2002). Cation Binding by Humic Substances. Cambridge: Cambridge University Press.

Tipping, E., and Hurley, M. A. (1988). A model of solid-solution interactions in acid organic soils, based on the complexation properties of humic substances. J. Soil Sci. 39, 505-519. doi: 10.1111/j.1365-2389.1988.tb01235.x

Van Epps, H. L. (2006). René Dubos: unearthing antibiotics. J. Exp. Med. 203:259. doi: $10.1084 /$ jem.2032fta

Vidal, A., Hirte, J., Bender, S. F., Mayer, J., Gattinger, A., Höschen, C., et al. (2018). Linking 3D structure and plant-microbe-soil carbon transfer in the rhizosphere. Front. Environ. Sci. 6:9. doi: 10.3389/fenvs.2018.00009

Waksman, S. A. (1925). What is humus? Proc. Natl. Acad. Sci. U.S.A. 11, 463-468. doi: 10.1073/pnas.11.8.463

Waksman, S. A. (1936). Humus. Origin, Chemical Composition and Importance Nature. New York, NY: Williams and Wilkins.

Waksman, S. A. (1958). My Life With the Microbes. London: The scientific Book Club.
Wander, M. (2004). "Soil organic matter fractions and their relevance to soil function," in Soil Organic Matter in Sustainable Agriculture, eds F. Magdoff and E. Well (Boca Raton, FL: CRC Press), 67-102.

Wander, M. M. (2009). "Agroecosystem integrity and the internal cycling of nutrients," in Agricultural Ecosystems: Unifying Concepts II, ed P. Bohlen and G. House (Boca Raton, FL: CRC Press), 137-166.

Weber, J., Chen, Y., Jamroz, E., and Miano, T. (2018). Preface: humic substances in the environment. J. Soils Sediments 18, 2665-2667. doi: 10.1007/s11368-018-2052-x

Wershaw, R. L. (1986). A new model for humic materials and their interactions with hydrophobic organic chemicals in soil-water or sediment-water systems. J. Contam. Hydrol. 1, 29-45. doi: 10.1016/0169-7722(86)90005-7

Wershaw, R. L. (1999). Molecular aggregation of humic substances. Soil Sci. 164, 803-813. doi: 10.1097/00010694-199911000-00004

Young, I. M., and Bengough, A. G. (2018). The search for the meaning of life in soil: an opinion. Eur. J. Soil Sci. 69, 31-38. doi: 10.1111/ejss.12514

Young, I. M., and Crawford, J. W. (2004). Interactions and self-organization in the soil-microbe complex. Science 304, 1634-1637. doi: 10.1126/science.1097394

Conflict of Interest Statement: The authors declare that the research was conducted in the absence of any commercial or financial relationships that could be construed as a potential conflict of interest.

Copyright $\odot 2019$ Baveye and Wander. This is an open-access article distributed under the terms of the Creative Commons Attribution License (CC BY). The use, distribution or reproduction in other forums is permitted, provided the original author(s) and the copyright owner(s) are credited and that the original publication in this journal is cited, in accordance with accepted academic practice. No use, distribution or reproduction is permitted which does not comply with these terms. 